\title{
Prevalence of Urogenital Schistosomiasis and Water, Sanitation and Hygiene Risk factors for transmission among Primary School Children in an urban endemic area of Kinondoni Municipality in Dar es Salaam, Tanzania
}

\section{Yonah Yangaza}

Muhimbili University of Health and Allied Sciences

Vivian Mushi ( $\nabla$ vmushi31@gmail.com)

Muhimbili University of Health and Allied Sciences https://orcid.org/0000-0001-9732-3057

Abdallah Zacharia

Muhimbili University of Health and Allied Sciences https://orcid.org/0000-0001-9380-6158

\section{Research Article}

Keywords: Urogenital schistosomiasis, Praziquantel, Primary school children, and Tanzania

Posted Date: February 17th, 2021

DOI: https://doi.org/10.21203/rs.3.rs-250219/v1

License: (c) (1) This work is licensed under a Creative Commons Attribution 4.0 International License. Read Full License 


\section{Abstract}

Objectives: To determine the prevalence of urogenital schistosomiasis and water, sanitation, and hygiene risk factors for transmission among primary school children in an urban endemic area of Kinondoni Municipality in Dar es Salaam, Tanzania.

Methods: A quantitative cross-sectional study was conducted between June and August 2020 to determine the prevalence of S.haematobium. A total of 250 urine samples were collected from primary school children, examined for haematuria using urinalysis test strips, and S.haematobium infection and intensity using the urine filtration technique. A structured questionnaire was used to collect information on water, sanitation, and hygiene risk factors that could influence the transmission of urogenital schistosomiasis. Data were entered and analyzed using SPSS version 22.

Results: Out of 250 primary school children recruited, 13(5.2\%) had haematuria, 3(1.2\%) had S. haematobium ova, and all were light-intensity infections. Among the risk factor assessed the following were significantly associated with the transmission of urogenital schistosomiasis; type of latrine used at home $(p=0.044)$, frequency of swimming $(p=0.030)$, the children who never swallowed praziquantel $(p<0.00)$, experienced side effects $(p<0.00)$, type of side effects experienced $(p=0.037)$, and reasons for not taking praziquantel in the last round of mass drug administration $(p=0.007)$.

Conclusions: The low prevalence of urogenital schistosomiasis indicates the ongoing transmission of the disease among primary school children. Frequency of swimming, type of latrines used at home, and nonuptake of praziquantel are the risk factors for the infection among primary school children. Therefore there is a need to provide health education to promote the uptake of praziquantel.

\section{Introduction}

Urogenital schistosomiasis is a disease of public health concern. The majority of urogenital schistosomiasis cases occurred to people living in Sub-Saharan Africa. It's estimated that 436 million people are at risk of acquiring urogenital schistosomiasis in Sub-Saharan Africa, and 112 million people are already infected with Schistosoma haematobium (S.haematobium). ${ }^{[1]}$ Urogenital schistosomiasis is responsible for the morbidity and mortality among the vulnerable population, whereby 103 million people had haematuria and dysuria, 100 million people had bladder morbidity, 19 million had kidney problems, and 0.162 mortality due to bladder and kidney cancers per year. ${ }^{[1]}$

Tanzania is among urinary schistosomiasis endemic countries with different levels of endemicity across the country. ${ }^{[2]}$ Urinary schistosomiasis is regarded as a disease of rural communities where the majority of residents are of poor socioeconomic status, with an inadequate supply of clean water, unimproved sanitation, and poor hygiene. ${ }^{[2]}$ However, evidence showed that urban settings are also affected by 
Dar es Salaam is among cities with historical evidence of urinary schistosomiasis infection. In the early 1980 s, the prevalence of urinary schistosomiasis in Dar es Salaam varied from $4 \%$ to $25 \%$ among school-aged children. ${ }^{[2]}$ As the years went on, the prevalence of urogenital schistosomiasis was increasing in Dar es Salaam up to $47.6 \%$ in the 1990 s. ${ }^{[6]}$ The high burden of urogenital schistosomiasis in Dar es Salaam alerted the need for preventive chemotherapy (PC), and hence, was one of the first regions in Tanzania (mainland) to implement school-based PC using praziquantel under the national schistosomiasis and soil-transmitted helminths control program in 2006. ${ }^{[7]}$

A study conducted in 2011 to assess the status of schistosomiasis in school-aged children after two rounds (2006 and 2007) of PC intervention in Dar es Salaam indicated a decrease in the prevalence of the disease, ${ }^{[8,9]}$ since then, little is known about the status of urogenital schistosomiasis among schoolaged children in Dar es Salaam. However, studies have been conducted in preschool-aged children and infants in 2015 and 2016, which reported the prevalence ranging from $1.2 \%$ to $1.9 \%$, indicating the ongoing transmission of urogenital schistosomiasis in Dar es Salaam. ${ }^{[10,11]}$ Therefore, this study was conducted to determine the current status of urogenital schistosomiasis, water, sanitation, and hygiene (WASH) risk factors, and uptake of praziquantel among primary school children in an urban endemic area of Kinondoni Municipality in Dar es Salaam, Tanzania. The information collected will be useful for modification of the existing schistosomiasis control program to ensure sustainable control of the disease as we are aiming for attaining the 2030 sustainable development goal three of health and wellbeing for all.

\section{Subjects And Methods}

\section{Description of the study area}

This study was conducted in Kinondoni municipality, one of the five municipalities of the Dar es Salaam region. According to the census of 2012 , the municipality has a total population of $1,775,049(914,247$ females and 860,802 males) with more than 446,504 household. ${ }^{[12]}$ The Municipality is boarded to the east by the Indian Ocean, to the north and west by the Coast Region. The area of Kinondoni has favorable climatic and ecological conditions that influence the survival of the Bulinus snail intermediate host of S.haematobium parasite. Kinondoni Municipality was selected because it's one of the few urban endemic areas for urogenital schistosomiasis in Tanzania, with the ongoing praziquantel treatment program for more than ten years. ${ }^{[10]}$

\section{Study design}

A school-based cross-sectional study involving a quantitative method of data collection was conducted between June and August 2020 to investigate the prevalence of urogenital schistosomiasis and WASH risk factors for transmission among primary school children in an urban endemic area of Kinondoni Municipality in Dar es Salaam, Tanzania. 


\section{Study population, inclusion and exclusion criteria}

The study population was primary school children from class four to six and aged seven to 15 years. All primary school children resident of Kinondoni municipality, aged seven to 15 from class four to six whose parents/guardian signed written informed consent form were eligible to participate. The students who were sick apart from urogenital schistosomiasis and whose parents/ guardians did not sign the written informed consent were excluded from participating in this study.

\section{Sample size determination and sampling procedure}

The sample size for this study was calculated from a formula for estimating sample size in a single cross-sectional survey.

$$
n=\underline{z^{2}} p(1-p)
$$

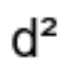

$\mathrm{n}$ = sample size

$z=$ level of confidence according to the standard normal distribution (for a level of confidence of $95 \%, z=$ 1.96)

$p=$ proportion of $S$. haematobium $(p=19.3 \%)$ found in previous study. ${ }^{[10]}$

$d=$ tolerated margin of error

\section{Thus, $n=(1.96)^{2}(19.3 \%)(100-19.3 \%)=239$}

$(5)^{2}$

239

\section{Assuming $10 \%$ non-response rate, adjusted sample was}

$$
\begin{gathered}
n=(1 / R \times 239)+239 \\
n=(10 / 100 \times 239)+239
\end{gathered}
$$

$n=263$

The calculated sample size was 263 primary school children. Kigogo ward was purposively selected Loading [MathJax]/jax/output/CommonHTML/jax.js somiasis endemicity for three and a half decades. ${ }^{[10]}$ Simple 
random selection was employed to select the representative school for sample collection, whereby Kigogo primary school was selected. Students from class four to six were sampled according to the total number of students in each class, meaning the class with a higher number of students contributed to higher sample size. A total of 100,120 and 30 students were sampled from classes four, five, and six respectively.

\section{Urine collection and laboratory analysis}

All of the sampled students were provided with labelled wide mouth dry plastic containers for the collection of the urine samples and were instructed on how to collect terminal urine. The collected urine samples were transferred to the Parasitology and Medical Entomology Laboratory of Muhimbili University of Health and Allied Sciences on the same day for the laboratory analysis.

In the laboratory; microhaematuria analysis was done using a chemical reagent strip (Cybow 10 Urinalysis Test Strip). For each sample, the reagent strip was dipped into the mixed urine for three minutes then removed and read. The change of strip colour was compared to the colour chart on the container of the strips to estimate the amount of blood in the urine. The results of microhaematuria were recorded as negative or positive.

Microscopic examination was done for each urine sample for detection of S.haematobium ova. The nuclepore membrane filtration technique was performed whereby $10 \mathrm{mls}$ of each urine sample was drawn using a $10 \mathrm{ml}$ plastic syringe and passed through a polycarbonate filter with a pore size of $12 \mathrm{um}$ to recover the eggs. All urine filters were carefully removed from filter holders and placed on the microscope slides then stained with Lugols iodine, and examined under the microscope with the magnification X10 and $\mathrm{X} 40$. The S.haematobium eggs were counted and reported as the number of eggs per $10 \mathrm{ml}$ of urine. The intensity of S.haematobium infection was differentiated according to WHO categories of 1-49 eggs $/ 10 \mathrm{ml}$ as light infection and $>50$ eggs/10 $\mathrm{ml}$ as heavy infection. ${ }^{[13]}$

\section{Questionnaire survey}

A structured questionnaire was prepared and used to collect information from primary school children. The questionnaire had three sections; the first section collected information on social-demographic characteristics of school children, the second section collected information on the uptake of praziquantel for prevention of urogenital schistosomiasis, and the third section collected information on WASH risk factors associated with the ongoing transmission of urogenital schistosomiasis among school children. Interviews were carried out after the collection of urine samples.

\section{Data analysis}

Data were checked for completeness, coded, entered, and cleaned using Statistical Package for the Social Sciences (SPSS) version 22. Descriptive statistics were computed to describe the prevalence of microhaematuria, prevalence, and intensity of S.haematobium ova according to social-demographic Loading [MathJax]/jax/output/CommonHTML/jax.js 
characteristics. The chi-square test $\left(\mathrm{x}^{2}\right)$ or Fisher's exact test and their related $\mathrm{p}$-values at a significance level of 0.05 were used to measure the association between the dependent variable (prevalence of urogenital schistosomiasis), and independent variables including social-demographic characteristics (age, sex, and class), uptake of praziquantel and WASH factors.

\section{Ethical considerations}

The ethical clearance was requested and obtained from the Muhimbili University of Health and Allied Sciences Institutional Review Board before the commencement of the study. Permission to conduct the study in Kinondoni Municipality was sought from the regional to district and school authorities. The written consent forms describing the objectives of the study, benefits and harms of participating in this study, and withdrawing rights from participation were distributed to eligible children to be given to their parents to read and sign if they consent their child to participate in this study. The children who were found positive for microhaematuria and S.haematobium were referred to a nearby dispensary for a further check-up, and treatment respectively.

\section{Results}

\section{Social demographic characteristics of the primary school children}

A total of 263 primary school children from class four to six were recruited in this study. However, only 250 provided urine samples and participated in the interview. Therefore, the rate of response was $93.9 \%$. Of the 250 children who participated; more than half (53\%) were males, the majority $(74 \%)$ were aged between 11 to 14 years, and nearly half (48\%) belonged to class five as shown in table one.

\section{Prevalence of microhaematuria among primary school children}

Table two shows the prevalence of microhaematuria among primary school children. The overall prevalence of microhaematuria was $5.2 \%$, being higher on females (3.2\%), children aged between 11 to 14 years, and class five children (2.8\%). There was a statistically significant association between the prevalence of microhaematuria and age groups of the children $(p<0.00)$.

\section{Prevalence of urogenital schistosomiasis among primary school children}

The overall prevalence of urogenital schistosomiasis among primary school children was $1.2 \%$. Males $(0.8 \%)$ of class five and aged between 11 to 14 years were more affected compared to females. There was no statistically significant association between the prevalence of urogenital schistosomiasis and sex, age groups, or class of the student as presented in table three.

\section{Intensity of urogenital schistosomiasis among primary school children}

All infected primary children had light infection intensities as described by World Health Organization (AIUn) an thn nntannrinn far annnnifinntinn of S. haematobium infection intensities. The intensity of Loading [MathJax]/jax/output/CommonHTML/jax.js 
urogenital schistosomiasis among primary school children ranged from 6 to 8 eggs/10mls of urine with the overall geometric mean of 6.95 eggs/ $10 \mathrm{~mL}$ of urine.

\section{Water, Sanitation and Hygiene Risk factors Associated with transmission of urogenital schistosomiasis among primary school children}

Out of 114 children living nearby water bodies, $61.4 \%$ were living near the Msimbazi river. More than half of the children were using piped water (62.4\%) and flush toilets $(58.8 \%)$. Of 137 children who had the habit of swimming in the Msimbazi river, $7.3 \%$ had the frequency of swimming daily. Only 70 children reported the habit of playing nearby water bodies, with $40 \%$ playing barefooted as shown in table four. Of all the risk factors assessed for association, only type of latrines used at home $(p=0.044)$ and frequency of swimming $(p=0.030)$ were associated with transmission of urogenital schistosomiasis.

\section{The uptake of praziquantel among primary school children in the last round of mass drug administration (MDA)}

The majority of the children (77.2\%) were able to participate in the last round of MDA. For children who did not participate in the last round of MDA the leading reasons were; fear of side effects $(57.9 \%)$ and being sick (22.8\%). Also, the majority of the children (84.4\%) who participated in MDA reported experiencing the side effects of the praziquantel, nausea (65\%) being the leading side effect as shown in table five. There was a statistically significant association between prevalence of urogenital schistosomiasis with the children who have never swallowed praziquantel $(p<0.00)$, experienced side effects $(p<0.00)$, type of side effects experienced $(p=0.037)$, and reasons for not taking praziquantel in the last round of MDA ( $p=0.007)$.

\section{Discussion}

Our findings indicate the low prevalence (1.2\%) of urogenital schistosomiasis among school children, and all infections were of light intensities. There is a decrease in the prevalence of urogenital schistosomiasis among school-aged children in Kinondoni Municipality from $41.6 \%$ in 1992 to $1.2 \%$ from this study. ${ }^{[6]}$ The decrease in prevalence could be due to a decade of praziquantel administration, ${ }^{[7,14]}$ high coverage of piped water supply, and latrine facilities. Despite the observed low prevalence, it's evident that transmission is still going on, and the primary school children could serve as a source of transmission to other community members.

Hematuria is a recognized clinical feature and morbidity indicator of S.haematobium infection. ${ }^{[15]}$ The prevalence of microhaematuria was higher (5.2\%) than the overall prevalence of urogenital schistosomiasis (1.2\%). The observed low prevalence of S.haematobium infection compared to the prevalence of microhaematuria is possible in low endemic settings where the shedding of eggs is low and thus difficult to detect eggs by the single filtration of a urine sample. Also, the high prevalence of microhaematuria could be due to the residual of menstruation blood, considering that the higher Loading [MathJax]/jax/output/CommonHTML/jax.js lales aged 11 to 14 years. Studies have reported the 
menstruation blood and persistence of bladder lesion for a long period than the actual time for shedding S. haematobium eggs as the reason for the high prevalence of microhaematuria. ${ }^{[16-18]}$

Inadequate water supply, poor sanitation and hygiene are among the risk factors for transmission of urogenital schistosomiasis in endemic settings. ${ }^{[19-21]}$ The findings from our study revealed that all of the infected students were not using the piped water, and most of them were living near the Msimbazi river. The frequent exposure to the water of the Msimbazi river when swimming, fetching water, crossing, playing barefooted, and utilization of water from the river for bathing were the risk factors identified from the students for the ongoing transmission of urogenital schistosomiasis in the study area despite the ongoing mass deworming. The findings are comparable with the previous studies on Tanzania, Nigeria, Senegal. ${ }^{[6,19,22,23]}$

The types of latrine used at home were statistically significantly associated with the prevalence of urogenital schistosomiasis. In this study, most of the affected children came from households with flush toilets. The owning and using the flush toilets at home does not prevent the children from acquiring urogenital schistosomiasis, especially if there are still frequent contacts to the river. There is the possibility that the children acquired the infection when swimming, bathing, or playing in the Msimbazi river. The findings of this study are in agreement with the study conducted in South Africa, which reported that all of the urogenital schistosomiasis-infected children came from the household owning different types of toilets. ${ }^{[24]}$

The frequency of swimming was statistically significantly associated with the prevalence of urogenital schistosomiasis. All of the infected students reported daily or weekly swimming in the Msimbazi river. Children tend to urinate in the water sources while swimming hence if the child is infected can contaminate the water sources. ${ }^{[25]}$ It has been reported that the frequency of water contact activities such as swimming to increase the risk of transmitting or acquiring the infection in endemic settings. ${ }^{[26-28]}$

Acceptability and uptake of praziquantel among primary school children are crucial for the control of urogenital schistosomiasis and for the prevention of long-term morbidity. ${ }^{[29]}$ The study findings revealed a statistically significant association between the uptake of the praziquantel and the prevalence of urogenital schistosomiasis. All of the infected students' self-reported never taking praziquantel drugs with the reason being; parents did not allow or absent at the school during praziquantel administration. The observed prevalence in this group is due to the fact that they have never taken the praziquantel in their lifetime. Studies have reported fear of side effects of the praziquantel, absent from the school during praziquantel distribution, parents not allowing their children to participate without specific reasons, and inadequate communication with the parents on the rationale of the praziquantel uptake as among the reasons that affect the acceptability and uptake of praziquantel treatment. ${ }^{[30,31]}$

The self-reported uptake of praziquantel was above the WHO target. ${ }^{[32]}$ This could be due to the ongoing neglected tropical diseases control program campaigns before the distribution of praziquantel. The Loading [MathJax]/jax/output/CommonHTML/jax.js le effects due to the uptake of praziquantel. The side effects 
attributed by the uptake of praziquantel tends to affect the acceptability and hence coverage of the praziquantel in the endemic settings. ${ }^{[30]}$

\section{Study Limitations}

The study had the following limitations; the urine samples were collected only once, which might have underestimated the prevalence of urogenital schistosomiasis among primary school children in the study area. Another limitation was recall bias; some of the questions required the primary school children to recall the previous year's information, such as the uptake of praziquantel treatments and side effects experienced this might have affected the accuracy of the information provided. Also, some information regarding WASH practices reported by children may be subjective and unreliable compared to observing them using a checklist.

\section{Abbreviations}

PC Preventive Chemotherapy

MDA Mass Drug Administration

SPSS Statistical Package for the Social Sciences

WASH Water, Sanitation and Hygiene.

\section{Declarations}

\section{Conflict of interest statement}

We declare that we have no conflict of interest.

\section{Acknowledgements}

We would like to thank the primary school children for their participation in this study, teachers and research assistants for their cooperation and support during fieldwork.

\section{Funding}

The authors received no financial support for the research, authorship, and publication of this study. This study was self-funded.

\section{Authors' contributions}

YY and VM conceptualized the study, YY did data collection and laboratory work, VM analyzed the data, and VM and $A Z$ drafted the manuscript. All authors read and approved the manuscript. 


\section{References}

1. World Health Organization. Epidemiology of Schistosomiasis. Available from: https://www.who.int/schistosomiasis/epidemiology/table/en/. Accessed 3 December 2020

2. Doumenge J-P, Mott KE, Chapuis O, Perrin MF, Reaud-Thomas G, Cheung C, et al. Atlas of the global distribution of schistosomiasis. Ceget-Cnrs 1987: 1-18.

3. M'Bra RK, Kone B, Yapi YG, Silué KD, Sy I, Vienneau D, et al. Risk factors for schistosomiasis in an urban area in northern Côte d'Ivoire. Infect Dis Poverty 2018;7(1):1-12.

4. Dabo A, Diarra AZ, Machault V, Touré O, Niambélé DS, Kanté A, et al. Urban schistosomiasis and associated determinant factors among school children in Bamako, Mali, West Africa. Infect Dis Poverty 2015;4(1):4.

5. Johnson CL, Appleton CC. Urban Schistosomiasis Transmission In Pietermaritzburg, South Africa. South African J Epidemiol Infect 2005;20(3):103-10.

6. Ndyomugyenyi R, Minjas JN. Urinary schistosomiasis in schoolchildren in Dar-es-Salaam, Tanzania, and the factors influencing its transmission. Ann Trop Med Parasitol 2001;95(7):697-706.

7. Imperial College London. Successful Mass Drug Administration across Tanzania | Imperial News. Available from: https://www.imperial.ac.uk/news/83321/successful-mass-drug-administrationacross-tanzania/. Accessed 19 December 2020

8. Mwakitalu ME, Malecela MN, Mosha FW, Simonsen PE. Urban schistosomiasis and soil transmitted helminthiases in young school children in Dar es Salaam and Tanga, Tanzania, after a decade of anthelminthic intervention. Acta Trop 2014;133(1):35-41.

9. Mwingira U. Evaluation of the health impact of integrated helminths control by preventive chemotherapy in the selected endemic districts of Tanzania. Doctoral Thesis 2017.

10. Ngwengweta SB, Tarimo S. Urinary schistosomiasis among preschool-age children in an endemic area of Kinondoni municipality, Dar es Salaam, Tanzania . Asian Pac J Trop Dis 2017;7(3):162-8.

11. Said K, Hella J, Knopp S, Nassoro T, Shija N, Aziz F, et al. Schistosoma, other helminth infections, and associated risk factors in preschool-aged children in urban Tanzania. PLoS Negl Trop Dis. 2017; 6(11).

12. National Bureau of Statistics-Ministry of Finance. 2012-Population and housing census 2013.

13. Montresor A, Gabrielli AF, Chitsulo L, Ichimori K, Mariotti S, Engels D, et al. Preventive chemotherapy and the fight against neglected tropical diseases. Expert Review of Anti-Infective Therapy 2012;10: 237-42.

14. Ministry of Health \& Social Welfare. Tanzania Mainland Strategic Master Plan for the Neglected Tropical Diseases Control Program- 2012-2017. MoHSW 2012.

15. Morenikeji O, Quazim J, Omoregie C, Hassan A, Nwuba R, Anumudu C, et al. A cross-sectional study on urogenital schistosomiasis in children; haematuria and proteinuria as diagnostic indicators in an endemic rural area of Nigeria. Afr Health Sci 2014;14(2):390-6. 
16. Krauth SJ, Greter H, Stete K, Coulibaly JT, Traoré SI, Ngandolo BNR, et al. All that is blood is not schistosomiasis: experiences with reagent strip testing for urogenital schistosomiasis with special consideration to very-low prevalence settings. Parasites and Vectors. 2015;8(1):584.

17. Doehring E, Reider F, Schmidt-Ehry G, Ehrich JHH. Reduction of pathological findings in urine and bladder lesions in infection with schistosoma haematobium after treatment with praziquantel. $J$ Infect Dis 1985;152(4):807-10.

18. Kosinski K, Adjei M, Bosompem K, Crocker J, Durant J. Effective control of Schistosoma haematobium infection in a Ghanaian community following installation of a water recreation area. PLoS Negl Trop Dis. 2012; 6(7): e1709

19. Grimes JET, Croll D, Harrison WE, Utzinger J, Freeman MC, Templeton MR. The Relationship between Water, Sanitation and Schistosomiasis: A Systematic Review and Meta-analysis. PLoS Neg/ Trop Dis 2014;8(12):e3296.

20. Grimes JE, Croll D, Harrison WE, Utzinger J, Freeman MC, Templeton MR. The roles of water, sanitation and hygiene in reducing schistosomiasis: A review. Parasites and Vectors 2015;8(1):1-16.

21. Evan Secor W. Water-based interventions for schistosomiasis control. Pathog Glob Health 2014;108(5):246-54.

22. Atalabi TE, Adoh SD, Eze KM. The current epidemiological status of urogenital schistosomiasis among primary school pupils in Katsina State, Nigeria: An imperative for a scale up of water and sanitation initiative and mass administration of medicines with Praziquantel. PLoS Negl Trop Dis 2018;12(7).

23. Senghor B, Diallo A, Sylla SN, Doucouré S, Ndiath MO, Gaayeb L, et al. Prevalence and intensity of urinary schistosomiasis among school children in the district of Niakhar, region of Fatick, Senegal. Parasites and Vectors 2014;7(1).

24. Kabuyaya M, Chimbari MJ, Mukaratirwa S. Infection status and risk factors associated with urinary schistosomiasis among school-going children in the Ndumo area of uMkhanyakude District in KwaZulu-Natal, South Africa two years post-treatment. Int J Infect Dis. 2018;71:100-6.

25. Rollinson D. A wake up call for urinary schistosomiasis: Reconciling research effort with public health importance. Parasitology. 2009;136 (1):593-610.

26. Mutsaka-Makuvaza MJ, Matsena-Zingoni Z, Katsidzira A, Tshuma C, Chin'ombe N, Zhou X-N, et al. Urogenital schistosomiasis and risk factors of infection in mothers and preschool children in an endemic district in Zimbabwe. Parasite and Vectors. 2019;12(1):427.

27. Chala B, Torben W. An Epidemiological Trend of Urogenital Schistosomiasis in Ethiopia. Front Public Heal. 2018; 5:6.

28. Afiukwa FN, Nwele DE, Uguru OE, Ibiam GA, Onwe CS, Ikpo AU, et al. Transmission Dynamics of Urogenital Schistosomiasis in the Rural Community of Ebonyi State, South Eastern Nigeria. $J$ Parasitol Res. 2019.

29. Toor J, Alsallaq R, Truscott JE, Turner HC, Werkman M, Gurarie D, et al. Are we on our way to Loading [MathJax]/jax/output/CommonHTML/jax.js niasis morbidity control using current world health 
organization guidelines? Clin Infect Dis. 2018;66:S245-52.

30. Muhumuza S, Olsen A, Katahoire A, Nuwaha F. Uptake of Preventive Treatment for Intestinal Schistosomiasis among School Children in Jinja District, Uganda: A Cross Sectional Study. PLoS One 2013;8(5).

31. Savioli L, Gabrielli AF, Montresor A, Chitsulo L, Engels D. Schistosomiasis control in Africa: 8 years after World Health Assembly Resolution 5419. Parasitology. 2009;136(13):1677-81.

32. WHO. Expert Committee on the Control of Schistosomiasis. Prevention and control of schistosomiasis and soil-transmitted helminthiasis: report of a WHO expert committee. World Health Organization; 2002. $57 \mathrm{p}$.

\section{Tables}

Table 1: Social-demographic characteristics primary school children $(n=250)$

\begin{tabular}{lcc}
\hline Variable & $\mathbf{n}(\%)$ & \\
\hline Sex & $\mathbf{9 5 \% \text { CI }}$ & \\
Females & $117(46.8)$ & $40-54$ \\
Males & $113(53.2)$ & $46-60$ \\
Age group & & \\
7-10 years & $49(19.6)$ & $14.5-25.0$ \\
11-14 years & $185(74)$ & $68.1-79.5$ \\
15-18 years & $16(6.4)$ & $3.6-9.5$ \\
Class & & \\
Class four & & \\
Class five & $100(40)$ & $33.6-45.6$ \\
Class six & $120(48)$ & $42-53.5$ \\
& $30(12)$ & $7.6-16$ \\
\hline
\end{tabular}

Table 2: Prevalence of microhaematuria among primary school children $(n=250)$ 


\begin{tabular}{lllll}
\hline Social-demographic characteristics & Total & $\begin{array}{l}\text { Microhaematuria } \\
\text { present }\end{array}$ & Fisher's exact & P-value \\
\hline Total & $\mathbf{2 5 0}$ & $\mathbf{1 3 ( 5 . 2 )}$ & & \\
Sex & & & 1.332 & 0.539 \\
$\begin{array}{l}\text { Females } \\
\text { Males }\end{array}$ & 117 & $8(3.2)$ & & \\
Age group & 133 & $5(2)$ & & \\
7-10 years & & & 12.054 & \\
11-14 years & 49 & $2(0.8)$ & & \\
15-18 years & 185 & $8(3.2)$ & & \\
& 16 & $3(1.2)$ & & \\
Class & & & 6.313 & \\
Class four & 100 & $3(1.2)$ & & \\
Class five & 120 & $7(2.8)$ & & \\
Class six & 30 & $3(1.2)$ & & \\
\hline
\end{tabular}

Table 3: Prevalence of urogenital schistosomiasis among primary school $(n=250)$

\begin{tabular}{lllll}
\hline $\begin{array}{l}\text { Social-demographic } \\
\text { characteristics }\end{array}$ & Total & $\begin{array}{l}\text { Microscopic observation of } \\
\text { S.haematobium }\end{array}$ & $\begin{array}{l}\text { Fisher's } \\
\text { exact }\end{array}$ & $\begin{array}{l}\text { p- } \\
\text { value }\end{array}$ \\
\hline Total & 250 & $\mathbf{3 ( 1 . 2 )}$ & & \\
Sex & 117 & $1(0.4)$ & 0.221 & 0.638 \\
$\begin{array}{l}\text { Females } \\
\text { Males }\end{array}$ & 133 & $2(0.8)$ & & \\
Age group & & & & \\
$7-10$ years & 49 & $1(0.4)$ & & \\
$\begin{array}{l}11-14 \text { years } \\
15-18 \text { years }\end{array}$ & 185 & $2(0.8)$ & & \\
Class & 16 & $0(0.0)$ & 0.775 \\
Class four & & & & \\
Class five & 100 & $1(0.4)$ & & \\
Class six & 120 & $2(0.8)$ & & \\
\hline
\end{tabular}

Table 4: Water, Sanitation and Hygiene Risk factors Associated with transmission of urogenital schistosomiasis among primary school children $(n=250)$ 


\begin{tabular}{|c|c|c|c|c|}
\hline Variable & $\mathbf{n}(\%)$ & $\begin{array}{l}\text { S.haematobium } \\
\text { positive }\end{array}$ & $\begin{array}{l}\text { Fisher's } \\
\text { exact }\end{array}$ & p-value \\
\hline $\begin{array}{l}\text { Live nearby wate } \\
\text { body } \\
\text { Yes } \\
\text { No }\end{array}$ & $\begin{array}{l}114(45.6) \\
136(54.4)\end{array}$ & $\begin{array}{l}2(0.8) \\
1(0.4)\end{array}$ & 0.543 & 0.461 \\
\hline $\begin{array}{l}\text { Type of water bod } \\
\text { near home } \\
\text { Pond } \\
\text { River }\end{array}$ & $\begin{array}{l}44(38.6) \\
70(61.4)\end{array}$ & $\begin{array}{l}0(0.0) \\
2(0.8)\end{array}$ & 1.887 & 0.301 \\
\hline $\begin{array}{l}\text { Source of the } \\
\text { water at home } \\
\text { Piped water } \\
\text { Dug well } \\
\text { River } \\
\text { Water kiosk }\end{array}$ & $\begin{array}{l}156(62.4) \\
38(15.2) \\
33(13.2) \\
23(9.2)\end{array}$ & $\begin{array}{l}0(0.0) \\
1(0.4) \\
1(0.4) \\
1(0.4)\end{array}$ & 4.151 & 0.292 \\
\hline $\begin{array}{l}\text { Type of latrines a } \\
\text { home } \\
\text { None } \\
\text { Pit latrine } \\
\text { Flush toilet } \\
\text { San plat latrine }\end{array}$ & $\begin{array}{l}11(4.4) \\
60(24) \\
147(58.8) \\
32(12.8)\end{array}$ & $\begin{array}{l}0(0.0) \\
1(0.4) \\
2(0.8) \\
0(0.0)\end{array}$ & 5.491 & 0.044 \\
\hline $\begin{array}{l}\text { Habit of swimmin } \\
\text { Yes } \\
\text { No }\end{array}$ & $\begin{array}{l}137(54.8) \\
113(45.2)\end{array}$ & $\begin{array}{l}2(0.8) \\
1(0.4)\end{array}$ & 0.173 & 0.678 \\
\hline $\begin{array}{l}\text { Frequency of } \\
\text { swimming } \\
\text { Daily } \\
\text { Weekly } \\
\text { >Weekly }\end{array}$ & $\begin{array}{l}10(7.3) \\
30(21.9) \\
97(70.8)\end{array}$ & $\begin{array}{l}1(0.4) \\
2(0.8) \\
0(0.0)\end{array}$ & 6.222 & 0.030 \\
\hline $\begin{array}{l}\text { Play nearby wate } \\
\text { bodies } \\
\text { Yes } \\
\text { No }\end{array}$ & $\begin{array}{l}70(28) \\
180(72)\end{array}$ & $\begin{array}{l}2(0.8) \\
1(0.4)\end{array}$ & 2.252 & 0.133 \\
\hline $\begin{array}{l}\text { Type of shoes } \\
\text { worn while playin }\end{array}$ & & & & \\
\hline $\begin{array}{l}\text { near water bodies } \\
\text { Closed shoes } \\
\text { Open shoes } \\
\text { No } \\
\text { shoes(barefooted) }\end{array}$ & $\begin{array}{l}25(35.7) \\
17(24.3) \\
28(40)\end{array}$ & $\begin{array}{l}0(0.0) \\
1(0.4) \\
2(0.8)\end{array}$ & 5.406 & 0.144 \\
\hline $\begin{array}{l}\text { Doing activities in } \\
\text { water sources } \\
\text { Yes } \\
\text { No }\end{array}$ & $\begin{array}{l}242(96.8) \\
8(3.2)\end{array}$ & $\begin{array}{l}3(1.2) \\
0(0.0)\end{array}$ & 0.1 & 0.751 \\
\hline $\begin{array}{l}\text { Type of activity } \\
\text { done in water } \\
\text { sources } \\
\text { Fetching water for } \\
\text { domestic and } \\
\text { irrigation }\end{array}$ & $57(23.5)$ & $1(0.4)$ & 4.66 & 0.458 \\
\hline $\begin{array}{l}\text { Washing dishes } \\
\text { Washing clothes } \\
\text { Cross point } \\
\text { Bathing }\end{array}$ & $\begin{array}{l}36(14.8) \\
87(36) \\
42(17.4) \\
20(8.3) \\
\end{array}$ & $\begin{array}{l}0(0.0) \\
0(0.0) \\
1(0.4) \\
1(0.4)\end{array}$ & & \\
\hline
\end{tabular}


Table 5: Self-reported uptake of praziquantel in the last round of MDA $(n=250)$

\begin{tabular}{|c|c|c|c|c|}
\hline Variable & $n(\%)$ & $\begin{array}{l}\text { S.haematobium } \\
\text { Positive }\end{array}$ & $\begin{array}{l}\text { Fisher's } \\
\text { exact }\end{array}$ & p-value \\
\hline \multicolumn{5}{|l|}{$\begin{array}{l}\text { Never swallowed } \\
\text { praziquantel during } \\
\text { MDA }\end{array}$} \\
\hline Yes & $34(13.6)$ & $3(1.2)$ & 19.3 & 0.000 \\
\hline No & $216(86.4)$ & $0(0.0)$ & & \\
\hline \multicolumn{5}{|l|}{$\begin{array}{l}\text { Swallowed } \\
\text { praziquantel in the } \\
\text { last round of MDA }\end{array}$} \\
\hline Yes & 193(77.2) & $0(0.0)$ & 3.32 & 0.048 \\
\hline No & $57(22.8)$ & $3(1.2)$ & & \\
\hline \multicolumn{5}{|l|}{$\begin{array}{l}\text { Reasons for not } \\
\text { taking praziquantel } \\
\text { in the last round }\end{array}$} \\
\hline Sick & $13(22.8)$ & $0(0.0)$ & 9.6 & 0.007 \\
\hline Fear of side effects & $33(57.9)$ & $0(0.0)$ & & \\
\hline $\begin{array}{l}\text { Parent did not allow } \\
\text { Absent from the } \\
\text { school }\end{array}$ & $\begin{array}{l}6(10.5) \\
5(8.8)\end{array}$ & $\begin{array}{l}2(0.8) \\
1(0.4)\end{array}$ & & \\
\hline \multicolumn{5}{|l|}{$\begin{array}{l}\text { Experienced } \\
\text { praziquantel side } \\
\text { effects }\end{array}$} \\
\hline Yes & $211(84.4)$ & $0(0.0)$ & 16.428 & 0.000 \\
\hline No & $39(15.6)$ & $3(1.2)$ & & \\
\hline \multicolumn{5}{|l|}{$\begin{array}{l}\text { Praziquantel side } \\
\text { effects } \\
\text { experienced }\end{array}$} \\
\hline Nausea & $137(65)$ & $0(0.0)$ & 13.495 & 0.037 \\
\hline Vomiting & $26(12.3)$ & $0(0.0)$ & & \\
\hline Dizziness & $12(5.7)$ & $0(0.0)$ & & \\
\hline Sweating & $9(4.2)$ & $0(0.0)$ & & \\
\hline Malaise & $8(3.8)$ & $0(0.0)$ & & \\
\hline Headache & $8(3.8)$ & $0(0.0)$ & & \\
\hline Upset stomach & $6(2.8)$ & $0(0.0)$ & & \\
\hline Itching & $5(2.4)$ & $0(0.0)$ & & \\
\hline
\end{tabular}

